\title{
The potential role of cell surface complement regulators and circulating CD4+CD25+ T-cells in the development of autoimmune myasthenia gravis
}

\author{
Mohamed Nasreldin Thabit Hamdoon ${ }^{1}$, Mona Fattouh ${ }^{2}$, Asmaa Nasr El-din ${ }^{2}$, Hassan M. Elnady ${ }^{1}$
}

${ }^{1}$ Department of Neurology, Sohag University, Sohag, Egypt

${ }^{2}$ Department of Microbiology and Immunology, Sohag University Hospital, Sohag, Egypt

\section{Type of article: Original}

\begin{abstract}
Introduction: $\mathrm{CD} 4+\mathrm{CD} 25+$ regulatory $\mathrm{T}$-lymphocytes (T-regs) and regulators of complement activity (RCA) involving CD55 and CD59 play an important role in the prevention of autoimmune diseases. However, their role in the pathogenesis of human autoimmune myasthenia gravis (MG) remains unclear. This study aimed to determine the frequency of peripheral blood T-regs and CD4+ T-helper (T-helper) cells and the red blood cells (RBCs) level of expression of CD55 and CD59 in MG patients.

Methods: Fourteen patients with MG in neurology outpatient clinics of Sohag University Hospital and Sohag General Hospital from March 2014 to December 2014, and 10 age-matched healthy controls participated in this case-control study. We did flowcytometric assessments of the percentage of peripheral T-regs and T-helper cells and the level of expression of CD55 and CD59 on RBCs in the peripheral blood of patients and controls.

Results: There was a statistically significant decrease in the percentage of peripheral blood T-regs and T-regs/Thelper cell ratio in the MG patients group. Moreover, the level of expression of CD55, CD59, and dual expression of CD55/CD59 on RBCs were statistically significantly lower in MG patients than those of healthy controls. However, regression analysis indicated that there was no significant correlation between all the measured parameters and disease duration or staging.

Conclusion: Functional defects in the T-regs and RCA may play a role in the pathogenesis of autoimmune MG and their functional modulation may represent an alternative therapeutic strategy for MG treatment.

Keywords: CD55; CD59; Myasthenia Gravis; Regulatory T-lymphocytes
\end{abstract}

\section{Introduction}

Acquired myasthenia gravis (MG), a prototypic humoral mediated autoimmune disease, is characterized by fatigable muscle weakness $(1,2)$. There is ample evidence that an autoimmune dysregualtion mechanism is responsible for the development of the disease, including the presence of auto antibodies in the neuromuscular junction, the ability of those auto antibodies to induce MG symptoms if injected into rodents, and the therapies that remove these auto antibodies, which usually decrease the symptoms of MG $(3,4)$. Auto antibodies to acetylecholine receptors (AntiAChR), muscle specific kinase (Anti-MuSK), low-density lipoprotein receptor-related protein 4, and aquaporin-4 were linked to the pathogenesis of MG (5-10). Complement activation mediated destruction of AChR, endocytosis of cross-linked AChR molecules, blockage of AChR binding site by anti-AChR auto antibodies, blocking of collagen $\mathrm{Q}$ binding to MuSK, and maybe others that are unknown are the proposed mechanisms of disease production in various clinical subtypes of $\mathrm{MG}(3,5,10,11)$. $\mathrm{CD} 3+\mathrm{CD} 4+\mathrm{T}$ lymphocytes (T-helper) play an important role in the pathogenesis of MG. Pathogenic anti-AChR auto antibodies are high-affinity immunoglobulins (IgGs), and their synthesis requires that activated T-helper cells interact with B cells, which produce the low-affinity anti-AChR auto antibodies. This interaction triggers somatic mutations of the IgGs genes, leading to synthesis of high-affinity auto antibodies (12-14).

\section{Corresponding author:}

Mohamed Nasreldin Thabit Hamdoon, Neurology Department, Sohag University Hospital, Sohag University, Madinat Nasser, Sohag, Egypt. Postal Code: 82524.

Tel: +201004934646, Email: Mohamed_hamdon@med.sohag.edu.eg

Received: November 02, 2015, Accepted: December 13, 2015, Published: January 2016

iThenticate screening: December 10, 2015, English editing: January 02, 2016, Quality control: January 06, 2016

(C) 2015 The Authors. This is an open access article under the terms of the Creative Commons Attribution-NonCommercialNoDerivs License, which permits use and distribution in any medium, provided the original work is properly cited, the use is non-commercial and no modifications or adaptations are made. 
From the above description, we can say that the effector mechanisms for induction of MG were thoroughly studied in the literature, but little is known about the role of the elements of the adaptive immune response in the development of MG. Active suppression of auto reactive T cells that escape the central mechanism of thymic clonal deletion and anergy, by CD4+CD25+ regulatory T cells (T-regs) plays a key role in the control of auto reactive $\mathrm{T}$ cells and the induction of peripheral tolerance in vivo (15-18). Despite the clear role of the T-regs in animal models of autoimmune diseases, only very limited and controversial information is available about the role of this T-cell population in the pathogenesis of human autoimmune diseases. Decrease in the number and/or the activity of circulating T-regs was reported in various autoimmune diseases, such as multiple sclerosis, type I diabetes mellitus, and others (19-22). There are many reports that showed decreased number or activity of T-regs in animal models of MG (23-26), however limited number of reports studied the T-regs in human patients with MG with conflicting results. Some studies showed reductions in T-regs numbers (27-29), impairment of its regulatory function $(30,31)$, or no defect $(32,33)$. One more mechanism of defense against immune attacks of self-antigens is the complement regulatory proteins. Decay-accelerating factor (DAF or CD55) and the membrane inhibitor of reactive lysis (MIRL or CD59) are membrane-bound proteins that restrict complement at different levels of the activation cascade. However, the role of those proteins in the pathogenesis of MG remains controversial. Some studies showed deficiency in the levels and/or functions of those proteins in animal models of MG (34-37), but other studies failed to confirm this (38). Moreover, the situation in human MG patients is unclear, since, to the best of our knowledge, there are no human studies available for those factors. As a step forward to further explain the role of the above described elements of adaptive immune response in the pathogenesis of MG in humans, we studied the percentages of T-helper, T-regs and the level of expression of CD55 and CD59 on red blood cells (RBCs) in the peripheral blood of human MG patients.

\section{Material and Methods}

\subsection{Research design and setting}

In this case-control study, 14 patients (12 females and 2 males) with MG were recruited from the neurology outpatient clinics of Sohag University Hospital and Sohag General Hospital between March 2014 and December 2014. The mean age $\pm \mathrm{SD}$ of the patients was $(32.36 \pm 6.54)$.

\subsection{Selection criteria and patients}

Several criteria were used for the clinical diagnosis of MG, i.e., 1) muscle weakness and rapid fatigue in one or more muscle groups; 2) muscle weakness aggravated by exercise and relieved by rest; and 3) a significant response to anti-cholinesterase drugs. Decremental response in repetitive nerve stimulation test and single fiber EMG were used to support the clinical diagnosis of MG. Osserman-Genkins' classification was used for the clinical classification of MG patients. Ten age- (33.9 \pm 7.25$)$ and gender- ( 8 females and 2 males) matched healthy controls without evidence of chronic inflammatory diseases participated in the study.

\subsection{Research ethics}

Written informed consent was taken from all study participants, and the study protocol was approved by the local Ethics Committee at Sohag University.

\subsection{Analysis of T cells population in peripheral blood}

Flowcytometric analysis of the percentage of T-helper and T-regs among the total lymphocytes population was carried out for all study participants. Peripheral blood samples were drawn in EDTA-containing test tubes. T-helper lymphocytes and T-regs were stained with monoclonal antibodies to CD4 (FITC), CD3 (PC5), and CD25 (PE) respectively. One hundred $\mu \mathrm{L}$ blood samples were placed into polystyrene tubes (Beckman Coulter, France) and subjected to three-color staining with $10 \mu \mathrm{L} /$ test of fluorochrome conjugated monoclonal antibodies (MoAbs). The antibodies used were anti CD4FITC, anti CD3PC5, and anti CD25PE (Beckman Coulter, France). After incubation for $20 \mathrm{~min}$ in the dark at room temperature, $1.0 \mathrm{~mL}$ of lysing reagent (Versalyse TM, Beckman Coulter, France) was added, and lysis was allowed for $10 \mathrm{~min}$ in the dark at room temperature. The cells were washed twice with phosphate-buffered saline prior to analysis. The cells were analyzed and 10,000 events were acquired using Beckman Coulter Epics-XL flowcytometer using System II software version 3.0 (Coulter, USA). The membrane intensities of CD3, CD4, and CD25 was estimated in the gated subpopulations by two parameter histograms. The intensities were proportional to the number of $\mathrm{CD} 3, \mathrm{CD} 4$, and CD25 epitopes on the cell membranes. We recorded the relative mean fluorescence intensity (MFI) of each sample, which indicated the amount of MoAbs bound to CD3, CD4, and CD25 expressed on peripheral blood cells. Gates for expression of CD25+ in the CD4+ population 
$(\mathrm{CD} 4+\mathrm{CD} 25+)$ were set. The CD25+ gate was adjusted to contain CD4+ cells that expressed CD25+ than the discrete population of CD4+ cells that does not express CD25.

\subsection{Analysis of RBCs expression of complement regulatory proteins}

Flowcytometric analysis of level of expression of complement regulatory proteins (CD55 and CD59) on RBCs was carried out for all study populations. Blood samples were collected in EDTA-containing test tubes. CD55-PE and CD59-FITC conjugated antibodies (Beckman Coulter, France) were used for flowcytometric analysis of CD55 and CD59, respectively. Diluted blood $(100 \mu \mathrm{L}$, with an optimal dilution with phosphate-buffered saline (PBS) to achieve 10,000 RBC/ $\mu \mathrm{L}$ ) was placed into polystyrene tubes (Beckman Coulter, France) and subjected to two-color staining with $10 \mu \mathrm{L} /$ test of MoAbs, i.e., anti CD55PE and anti CD59FITC (Beckman Coulter, France). After incubation for $20 \mathrm{~min}$ in the dark at room temperature, the samples were resuspended in $1 \mathrm{~mL}$ of PBS. After incubation for an additional $20 \mathrm{~min}$ under the same conditions, the cells were analyzed by the flowcytometer, and 10,000 events were acquired by Beckman Coulter Epics-XL flow cytometer using System II software version 3.0 (Coulter, USA). Membrane intensities of CD55 and CD59, which were proportional to the number of CD55 and CD59 epitopes, respectively, on the RBCs membranes, were estimated in the gated subpopulations by twoparameter histograms. The relative MFI of each sample expressed on then RBCs was recorded, indicating the amount of MoAbs bound to CD59 or CD55.

\subsection{Statistical analysis}

The student's t-test was used to analyze both the $\mathrm{T}$ reg/T-helper ratio and the percentages of CD55 and CD59 expression. Demographic variables and baseline clinical characteristics of the two groups were compared using student's t-test and the chi-squared test. The results were considered to be significant if $\mathrm{P}<0.05$. The SPSS version 16 software program was used for statistical analyses. If not mentioned otherwise, data were given as mean \pm SEM. Other appropriate tests are described in the results section.

\section{Results}

The various clinical and demographic data of all patients are presented in Table 1 . There were no statistically significant differences between patients and controls regarding age and gender. The total percentages of T-helper cells among the total lymphocytic count of patients and healthy controls were $55.5 \pm 3.74$ and $62.07 \pm 2.65$, respectively. However, the percentages of T-regs subtype were $1.66 \pm 0.27$ and $3.76 \pm 0.66$ for patients and healthy controls, respectively. The T-regs/T-helper ratios were $0.029 \pm 0.003$ and $0.06 \pm 0.01$ for patients and healthy controls, respectively. The student's t-test indicated that there was a statistically significant difference between patients and healthy controls regarding the T-regs percentages and T-regs/T-helper ratio $(\mathrm{t}=-3.295, \mathrm{p}=0.003 ; \mathrm{t}=$ $3.141, \mathrm{p}=0.005$ ) (Figures 1, 2). However, there was no significant difference between patients and healthy controls regarding $\mathrm{T}$-helper percentages $(\mathrm{t}=-1.32, \mathrm{p}=0.2)$. Regression analysis indicated that there were no significant correlations between T-regs percentage and T-regs/T-helper ratio and disease duration or staging in the patients.

Table 1. Demographic data of MG patients

\begin{tabular}{|l|l|l|l|l|}
\hline Patient & Age (years) & Gender $^{1}$ & Disease duration (years) & Osserman-Genkins Classification \\
\hline 1 & 39 & F & 5 & IIB (Moderate generalized MG) \\
\hline 2 & 33 & F & 2 & I (Ocular MG) \\
\hline 3 & 28 & F & 8 & IV (Late severe MG) \\
\hline 4 & 26 & F & 1 & IIA (Mild generalized MG) \\
\hline 5 & 43 & M & $5 / 12$ & IIA (Mild generalized MG \\
\hline 6 & 24 & F & $2 / 12$ & III (acute fulminating MG) \\
\hline 7 & 35 & F & 1 & IIA (Mild generalized MG) \\
\hline 8 & 30 & F & 3 & IIB (Moderate generalized MG) \\
\hline 9 & 40 & F & 4 & IIB (Moderate generalized MG) \\
\hline 10 & 42 & F & 2 & IIB (Moderate generalized MG) \\
\hline 11 & 27 & F & $3 / 12$ & I (ocular MG) \\
\hline 12 & 24 & F & 1 & IIA (Mild generalized MG \\
\hline 13 & 32 & F & 3 & IIA (Mild generalized MG) \\
\hline 14 & 30 & M & 2 & IIA (Mild generalized MG) \\
\hline
\end{tabular}

1: $\mathrm{M}=$ male, $\mathrm{F}=$ female 


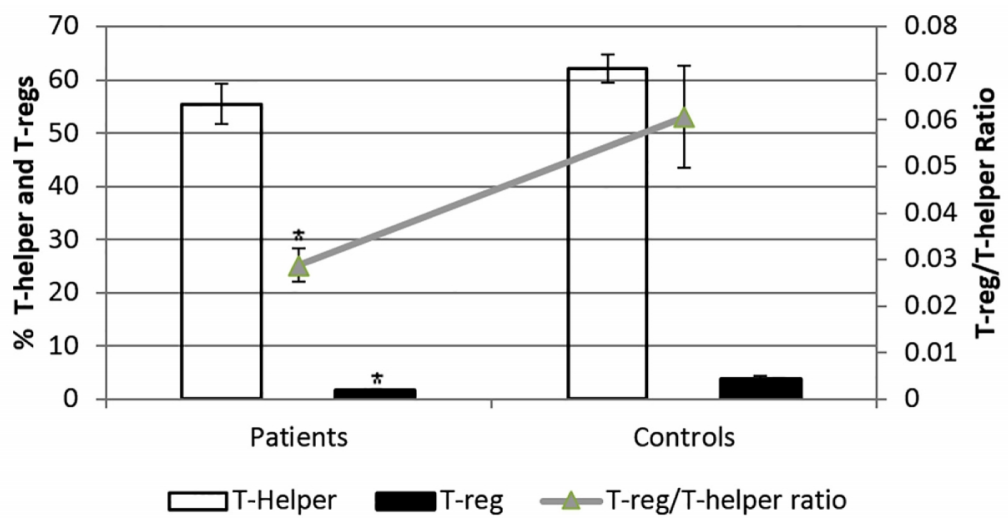

Figure 1. There is statistically significant difference between patients and healthy controls regarding the T-regs percentages and T-regs/T-helper ratio
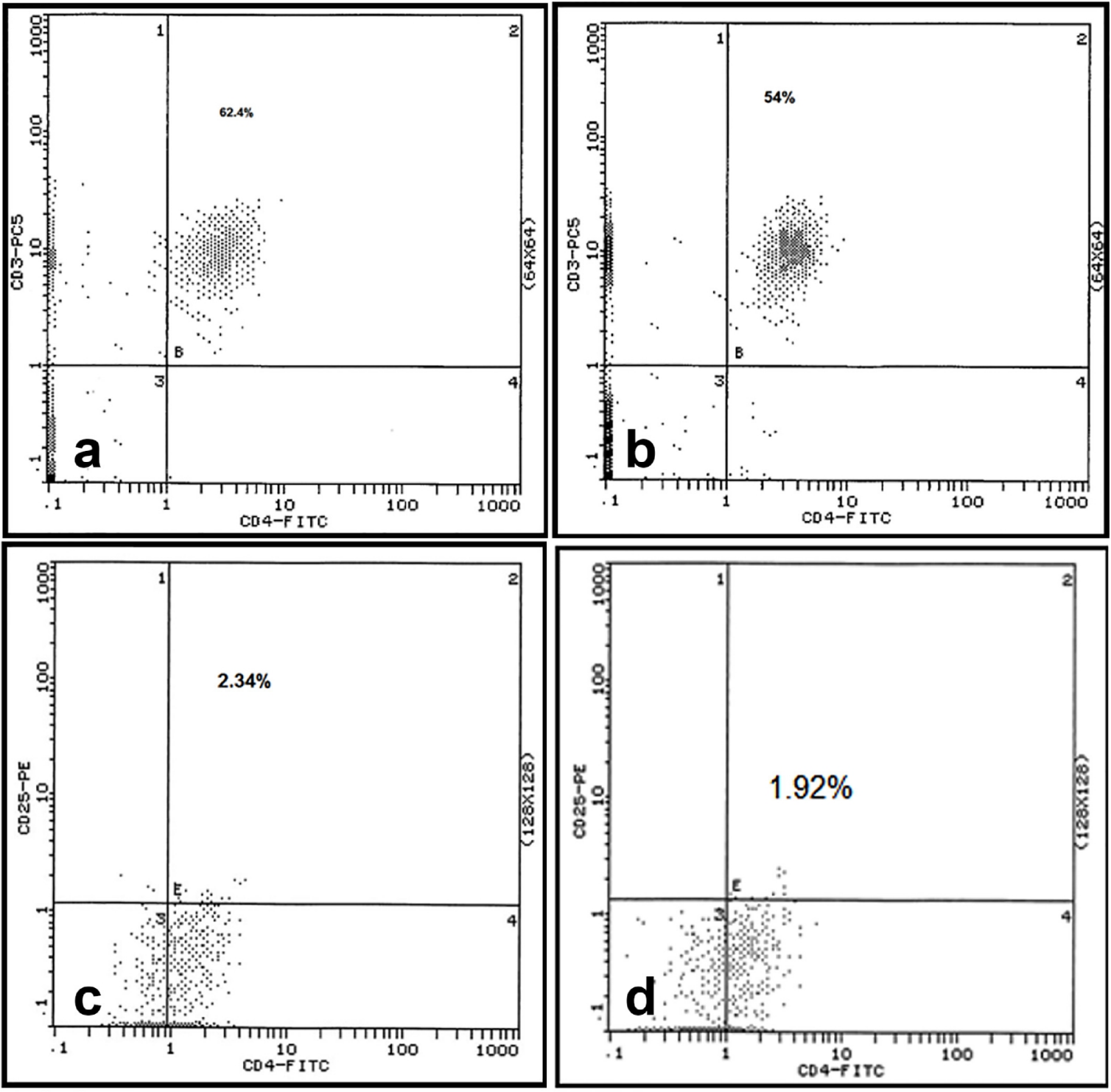

Figure 2. Flowcytometry dot plots representative histograms demonstrating the percentage of T-helper lymphocytes in control subject (a), and in MG patient (b); and T-regs percentages in a control subject (c), and in MG patient (d). 
The total percentages of CD55 expressing RBCs in peripheral blood of patients and healthy controls were $55.69 \pm$ 3.68 and $95.9 \pm 1.27$, respectively. The percentages of CD59 expressing RBCs were $67.07 \pm 2.89$ and $84.15 \pm 2.30$ for patients and healthy controls, respectively. The percentages of RBCs dually expressing both CD55 and CD59 were $29.26 \pm 3.08$ and $52.21 \pm 4.9$ for patients and healthy controls, respectively. The student's t-test indicated that there was a statistically significant difference between patients and healthy controls in the percentages of RBCs expressing CD55, CD59 and both CD55/CD59 ( $\mathrm{t}=8.919, \mathrm{p}<0.001 ; \mathrm{t}=4.33, \mathrm{p}<0.001 ; \mathrm{t}=4.142, \mathrm{p}<0.001$, respectively) (Figures 3,4). Regression analysis indicated that there was no significant correlation between $\mathrm{T}$ regs/T-helper ratio, CD55 expressing RBCs, CD59 expressing RBCs, and finally CD55/CD59 dually expressing $\mathrm{RBCs}$ percentages and disease duration or staging.

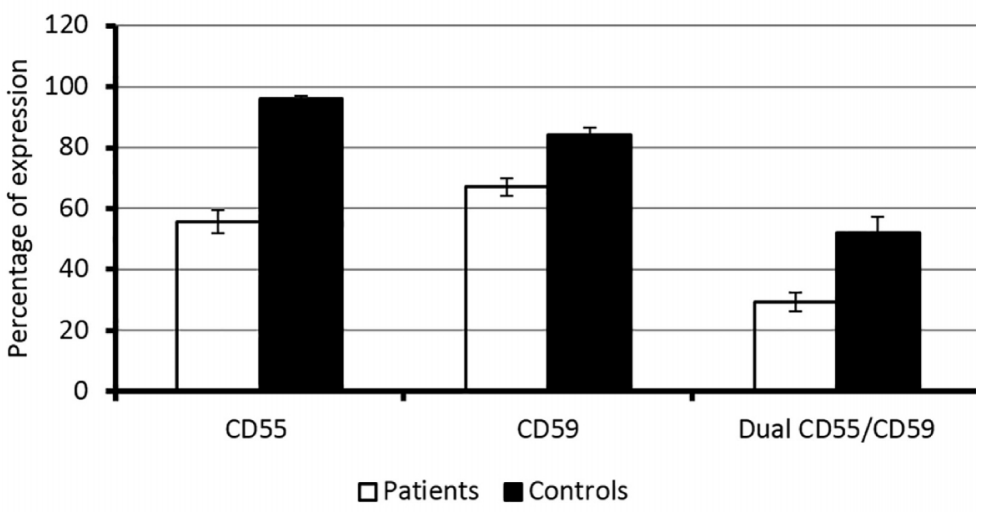

Figure 3. There is statistically significant difference between patients and healthy controls regarding the percentage of RBCs expressing CD55, CD59, and dually expressing CD55/CD59
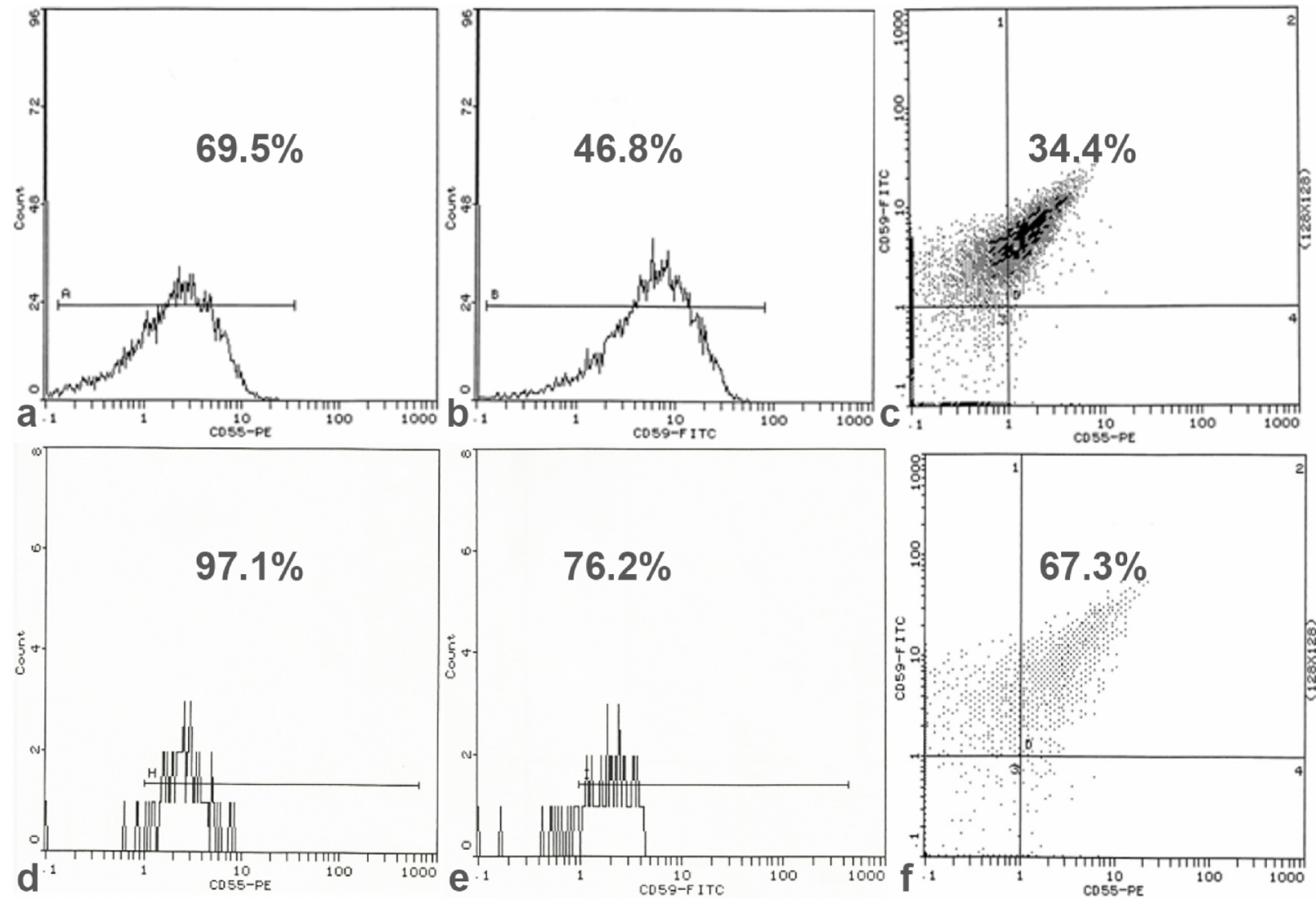

Figure 4. Flowcytometry dot plots representative histograms demonstrating the percentage of RBCs expressing CD55, CD59 and dually expressing CD55/CD59 in MG patient (a, b, and c), and in healthy control (d, e, and f). 


\section{Discussion}

We found that the immunological profile of patients with MG was characterized by a reduction in the percentage of T-regs and T-regs/T-helper ratio. Moreover, there was a reduction in the peripheral blood RBCs level of expression of complement regulatory proteins (CD55, CD59) in comparison to the control group, but the reductions of the $\mathrm{T}$ regs percentage, the CD55, and the CD59 were not correlated to the severity of the disease. The main mechanism of immune tolerance to self-antigens was achieved initially during thymic development by active clonal deletion of the potentially auto reactive $\mathrm{T}$ cells. However, in normal individuals, some of these pathogenic cells, including those with auto reactivity to AChR, overcame clonal deletion. Those auto reactive $\mathrm{T}$ cells are caught by peripheral tolerance mechanisms. One of the most important peripheral tolerance mechanisms is the T-regs (39). T-regs are a subpopulation of $\mathrm{T}$ cells that suppress auto-reactive $\mathrm{T}$ cells to maintain self-tolerance (40). Concerning the pathogenesis of autoimmune disease, it has been hypothesized that a functional deficiency in $\mathrm{T}$-regs could result in the failure to suppress auto-reactive $\mathrm{T}$ cell responses $(41,42)$. As outlined in the Introduction, a deficiency or dysfunction of T-regs can contribute to the pathogenesis of many autoimmune diseases (43-46). T-regs actively mediate self-tolerance and suppress autoimmunity by inhibiting activation, proliferation, and cytokine production of the effector auto reactive $T$ cells that arise de novo or escape thymic filtering mechanisms. The transcription factor forkhead box protein P3 (FOXP3) is expressed on the surface of T-regs and is considered to be the master regulatory mechanism for the development and functioning of these cells $(40,47)$. A dysfunction or deficiency of T-regs also has been reported in both animal models and human patients with MG. There are many reports that have shown a decreased number or decreased activity of T-regs in animal models of MG (23-26). One study of MG patients indicated that the number of T-regs in the blood of untreated myasthenia gravis patients was significantly lower than in age-matched healthy subjects; however, it was normal or elevated in patients who were undergoing immunosuppressive treatment (27). One study used a more precise method for detection, including the detection of cells with FOXP3 surface protein and CD25+ (high), and it also showed a reduction in the frequency of T-regs in MG patients compared to healthy controls (28). Moreover, Masuda et al. found that FOXP3 expression and T-regs number were lower in MG patients than in healthy controls (29). Other studies have shown only dysfunction in Tregs activity. Thiruppathi et al. used surface CD4+, CD25+ (high), and CD127- (low) expression to isolate a relatively pure population of T-regs. They established that, in MG patients, there was no alteration in the relative numbers of T-regs within the peripheral T cell pool. However, in vitro proliferation assays showed that the T-regsmediated suppression of auto reactive $\mathrm{T}$ cells was impaired in $\mathrm{MG}$ patients and was associated with a reduced expression of FOXP3 in isolated T-regs 30. Other studies have shown that both mRNA and the protein expression level of FOXP3 in CD4+CD25+ T-regs were down-regulated dramatically. This was accompanied by a severe functional defect in $\mathrm{CD} 4+\mathrm{CD} 25+\mathrm{T}$-regs regulatory activity when they were co-cultured with autologous CD4+CD25- T cells. In this case, the functional defect occurred although the reservoir of CD4+CD25+ T-regs was not changed in the peripheral blood from MG patients (31).

A complement system is defined as a sequentially-activated, soluble serum proteins cascade, leading to cell death through direct lysis and/or phagocytic activation. A complement system can be activated through three pathways, i.e., the classic pathway (antibody dependent), alternative pathway (spontaneous), and the lectin pathway (mediated by mannose-binding lectins pathway). All of these pathways end by formation of anaphylatoxins (C3a and C5a), which mediate inflammation, opsonin $(\mathrm{C} 3 \mathrm{~b})$, which mediates opsonization and promote phagocytosis, and the formation of membrane attack complex (MAC), which leads to direct cell lysis (48-50). CD55 and CD59 restrict complement activation by inhibiting C3/C5 convertases' activities and the formation of the membrane attack complex, respectively $(51,52)$. Many studies have explored the role of complement regulatory proteins in animal models of MG. The studies have shown that diminished intrinsic complement regulatory activity may contribute to the susceptibility to MG (35) and increase the expression of CD55 and CD59, which protects against the loss of acetylcholine receptors and protects against muscle weakness (34). Actively immunized experimental MG mice deficient in either CD55 or CD59 had significant differences in their adaptive immune responses. They also had worsened disease outcomes associated with the increased levels of serum cytokines, the modified production of acetylcholine receptor antibodies, and enhanced complement deposition at the neuromuscular junction (36, 37). A common occurrence in human $\mathrm{MG}$ is the propensity for the involvement of the extraoccular muscles. In mice, profiling the gene expression using a DNA microarray has verified that CD55 gene expression is five to seven times lower in extraoccular muscles than in skeletal muscles. This provides additional evidence for the role of CD55 in pathogenesis of MG (53). To the best of our knowledge, we do not have studies of human patients with MG in which the role of CD55 and CD59 was expressed. 


\section{Conclusions}

From these findings, we concluded that impaired immune regulation characterized by quantitative defects in the Tregs and in the inhibition of the complement cascade occurs in patients with MG. Nevertheless, MG patients are still treated with non-specific global immunosuppression that is associated with severe chronic side effects. We believe that modulation of these defects alone or in combination might aid in the development of future treatment strategies that would reduce MG symptoms with highest efficacy and lowest side effect profile. Further improvement of novel treatment methods based on inhibition of the complement system will open a new page in management of patients with MG, such as the use of natural complement inhibitors as humanized CD55.

\section{Acknowledgments:}

We acknowledge all authors who shared in conducting the research and writing the paper.

\section{Conflict of Interest:}

There is no conflict of interest to be declared.

Authors' contributions:

All authors contributed to this project and article equally. All authors read and approved the final manuscript.

\section{References}

1) Ha JC, Richman DP. Myasthenia gravis and related disorders: Pathology and molecular pathogenesis. Biochim Biophys Acta. 2015; 1852(4): 651-7. doi: 10.1016/j.bbadis.2014.11.022, PMID: 25486268.

2) Sieb JP. Myasthenia gravis: an update for the clinician. Clin Exp Immunol. 2014; 175(3): 408-18. doi: 10.1111/cei.12217, PMID: 24117026, PMCID: PMC3927901.

3) Conti-Fine BM, Milani M, Kaminski HJ. Myasthenia gravis: past, present, and future. J Clin Invest. 2006; 116(11): 2843-54. doi: 10.1172/JCI29894, PMID: 17080188, PMCID: PMC1626141.

4) Vincent A. Unravelling the pathogenesis of myasthenia gravis. Nat Rev Immunol. 2002; 2(10): 797-804. doi: 10.1038/nri916, PMID: 12360217.

5) Higuchi O, Hamuro J, Motomura M, Yamanashi Y. Autoantibodies to low-density lipoprotein receptorrelated protein 4 in myasthenia gravis. Ann Neurol. 2011; 69(2): 418-22. doi: 10.1002/ana.22312, PMID: 21387385.

6) Jarius S, Paul F, Franciotta D, de Seze J, Münch C, Salvetti M, et al. Neuromyelitis optica spectrum disorders in patients with myasthenia gravis: ten new aquaporin-4 antibody positive cases and a review of the literature. Mult Scler. 2012; 18(8): 1135-43. doi: 10.1177/1352458511431728, PMID: 22183934.

7) Pevzner A, Schoser B, Peters K, Cosma NC, Karakatsani A, Schalke B, et al. Anti-LRP4 autoantibodies in AChR- and MuSK-antibody-negative myasthenia gravis. J Neurol. 2012; 259(3): 427-35. doi: 10.1007/s00415-011-6194-7, PMID: 21814823.

8) Vaknin-Dembinsky A, Abramsky O, Petrou P, Ben-Hur T, Gotkine M, Brill L, et al. Myasthenia gravisassociated neuromyelitis optica-like disease: an immunological link between the central nervous system and muscle? Arch Neurol. 2011; 68(12): 1557-61. doi: 10.1001/archneurol.2011.200, PMID: 21825214.

9) Zhang B, Luo S, Wang Q, Suzuki T, Xiong WC, Mei L. LRP4 serves as a coreceptor of agrin. Neuron. 2008; 60(2): 285-97. doi: 10.1016/j.neuron.2008.10.006, PMID: 18957220, PMCID: PMC2743173.

10) Zhang B, Tzartos JS, Belimezi M, Ragheb S, Bealmear B, Lewis RA, et al. Autoantibodies to lipoproteinrelated protein 4 in patients with double-seronegative myasthenia gravis. Arch Neurol. 2012; 69(4): 445-51. doi: 10.1001/archneurol.2011.2393, PMID: 22158716.

11) Kawakami Y, Ito M, Hirayama M, Sahashi K, Ohkawara B, Masuda A, et al. Anti-MuSK autoantibodies block binding of collagen $Q$ to MuSK. Neurology. 2011; 77(20): 1819-26. doi: 10.1212/WNL.0b013e318237f660, PMID: 22013178, PMCID: PMC3233209.

12) Eng H, Lefvert AK, Mellstedt H, Osterborg A. Human monoclonal immunoglobulins that bind the human acetylcholine receptor. Eur J Immunol. 1987; 17(12): 1867-9. doi: 10.1002/eji.1830171232, PMID: 3691628.

13) Wang ZY, Okita DK, Howard J Jr, Conti-Fine BM. T-cell recognition of muscle acetylcholine receptor subunits in generalized and ocular myasthenia gravis. Neurology. 1998; 50(4): 1045-54. doi: 10.1212/WNL.50.4.1045, PMID: 9566393.

14) Whiting PJ, Vincent A, Newsom-Davis J. Acetylcholine receptor antibody characteristics in myasthenia gravis. Fractionation of alpha-bungarotoxin binding site antibodies and their relationship to IgG subclass. J Neuroimmunol. 1983; 5(1): 1-9. doi: 10.1016/0165-5728(83)90022-X. 
15) Sakaguchi S. Regulatory T cells: key controllers of immunologic self-tolerance. Cell. 2000; 101(5): 455-8. doi: 10.1016/S0092-8674(00)80856-9.

16) Sakaguchi S, Sakaguchi N, Asano M, Itoh M, Toda M. Immunologic self-tolerance maintained by activated $\mathrm{T}$ cells expressing IL-2 receptor alpha-chains (CD25). Breakdown of a single mechanism of self-tolerance causes various autoimmune diseases. J Immunol. 1995; 155(3): 1151-64. PMID: 7636184.

17) Saoudi A, Seddon B, Fowell D, Mason D. The thymus contains a high frequency of cells that prevent autoimmune diabetes on transfer into prediabetic recipients. J Exp Med. 1996; 184(6): 2393-8. doi: 10.1084/jem.184.6.2393, PMID: 8976193, PMCID: PMC2196374.

18) Shevach EM, Piccirillo CA, Thornton AM, McHugh RS. Control of T cell activation by CD4+CD25+ suppressor T cells. Novartis Found Symp. 2003; 252: 24-36; discussion -44, 106-14.

19) Boyer O, Saadoun D, Abriol J, Dodille M, Piette JC, Cacoub P, et al. CD4+CD25+ regulatory T-cell deficiency in patients with hepatitis C-mixed cryoglobulinemia vasculitis. Blood. 2004; 103(9): 3428-30. doi: 10.1182/blood-2003-07-2598, PMID: 14684420.

20) Cao D, Malmstrom V, Baecher-Allan C, Hafler D, Klareskog L, Trollmo C. Isolation and functional characterization of regulatory $\mathrm{CD} 25$ brightCD4 $+\mathrm{T}$ cells from the target organ of patients with rheumatoid arthritis. Eur J Immunol. 2003; 33(1): 215-23. doi: 10.1002/immu.200390024, PMID: 12594850.

21) Kukreja A, Cost G, Marker J, Zhang C, Sun Z, Lin-Su K, et al. Multiple immuno-regulatory defects in type-1 diabetes. J Clin Invest. 2002; 109(1): 131-40. doi: 10.1172/JCI0213605, PMID: 11781358, PMCID: PMC150819.

22) Putheti P, Morris M, Stawiarz L, Teleshova N, Kivisäkk P, Pashenkov M, et al. Multiple sclerosis: a study of chemokine receptors and regulatory T cells in relation to MRI variables. Eur J Neurol. 2003; 10(5):52935. doi: 10.1046/j.1468-1331.2003.00638.x, PMID: 12940835.

23) Aricha R, Feferman T, Berrih-Aknin S, Fuchs S, Souroujon MC. Experimental myasthenia gravis in Airedeficient mice: a link between Aire and regulatory T cells. Ann N Y Acad Sci. 2012; 1275:107-13. doi: 10.1111/j.1749-6632.2012.06843.x, PMID: 23278585.

24) Gertel-Lapter S, Mizrachi K, Berrih-Aknin S, Fuchs S, Souroujon MC. Impairment of regulatory T cells in myasthenia gravis: studies in an experimental model. Autoimmun Rev. 2013; 12(9): 894-903. doi: 10.1016/j.autrev.2013.03.009, PMID: 23535156.

25) Sheng JR, Muthusamy T, Prabhakar BS, Meriggioli MN. GM-CSF-induced regulatory T cells selectively inhibit anti-acetylcholine receptor-specific immune responses in experimental myasthenia gravis. J Neuroimmunol. 2011; 240-41: 65-73. doi: 10.1016/j.jneuroim.2011.10.010, PMID: 22099723, PMCID: PMC3234297.

26) Thiruppathi M, Rowin J, Li Jiang Q, Sheng JR, Prabhakar BS, Meriggioli MN. Functional defect in regulatory T cells in myasthenia gravis. Ann N Y Acad Sci. 2012; 1274: 68-76. doi: 10.1111/j.17496632.2012.06840.x, PMID: 23252899, PMCID: PMC3531815.

27) Fattorossi A, Battaglia A, Buzzonetti A, Ciaraffa F, Scambia G, Evoli A. Circulating and thymic CD4 CD25 T regulatory cells in myasthenia gravis: effect of immunosuppressive treatment. Immunology. 2005; 116(1): 134-41. doi: 10.1111/j.1365-2567.2005.02220.x, PMID: 16108825, PMCID: PMC1802400.

28) Li X, Xiao BG, Xi JY, Lu CZ, Lu JH. Decrease of CD4(+)CD25(high)Foxp3(+) regulatory T cells and elevation of CD19(+)BAFF-R(+) B cells and soluble ICAM-1 in myasthenia gravis. Clin Immunol. 2008; 126(2): 180-8. doi: 10.1016/j.clim.2007.10.001, PMID: 18054287.

29) Masuda M, Matsumoto M, Tanaka S, Nakajima K, Yamada N, Ido N, et al. Clinical implication of peripheral $\mathrm{CD} 4+\mathrm{CD} 25+$ regulatory $\mathrm{T}$ cells and Th17 cells in myasthenia gravis patients. J Neuroimmunol. 2010; 225(1-2): 123-31. doi: 10.1016/j.jneuroim.2010.03.016, PMID: 20472307.

30) Thiruppathi M, Rowin J, Ganesh B, Sheng JR, Prabhakar BS, Meriggioli MN. Impaired regulatory function in circulating CD4(+)CD25(high)CD127(low/-) T cells in patients with myasthenia gravis. Clin Immunol. 2012; 145(3): 209-23. doi: 10.1016/j.clim.2012.09.012, PMID: 23110942, PMCID: PMC3501560.

31) Zhang Y, Wang HB, Chi LJ, Wang WZ. The role of FoxP3+CD4+CD25hi Tregs in the pathogenesis of myasthenia gravis. Immunol Lett. 2009; 122(1): 52-7. doi: 10.1016/j.imlet.2008.11.015, PMID: 19111574.

32) Huang Y, Pirskanen R, Ciscombe R, Link H, Lefvert AK. Circulating CD4+CD25+ and CD4+CD25- T cells in myasthenia gravis. Ann N Y Acad Sci. 2003; 998: 318-9. doi: 10.1196/annals.1254.034, PMID: 14592889.

33) Huang YM, Pirskanen R, Giscombe R, Link H, Lefvert AK. Circulating CD4+CD25+ and CD4+CD25+ T cells in myasthenia gravis and in relation to thymectomy. Scand J Immunol. 2004; 59(4): 408-14. doi: 10.1111/j.0300-9475.2004.01410.x, PMID: 15049785. 
34) Kaminski HJ, Kusner LL, Richmonds C, Medof ME, Lin F. Deficiency of decay accelerating factor and CD59 leads to crisis in experimental myasthenia. Exp Neurol. 2006; 202(2): 287-93. doi: 10.1016/j.expneurol.2006.06.003, PMID: 16859686.

35) Kaminski HJ, Li Z, Richmonds C, Lin F, Medof ME. Complement regulators in extraocular muscle and experimental autoimmune myasthenia gravis. Exp Neurol. 2004; 189(2): 333-42. doi: 10.1016/j.expneurol.2004.06.005, PMID: 15380483.

36) Lin F, Kaminski HJ, Conti-Fine BM, Wang W, Richmonds C, Medof ME. Markedly enhanced susceptibility to experimental autoimmune myasthenia gravis in the absence of decay-accelerating factor protection. J Clin Invest. 2002; 110(9): 1269-74. doi: 10.1172/JCI0216086, PMID: 12417565, PMCID: PMC151616.

37) Soltys J, Halperin JA, Xuebin Q. DAF/CD55 and Protectin/CD59 modulate adaptive immunity and disease outcome in experimental autoimmune myasthenia gravis. J Neuroimmunol. 2012; 244(1-2): 63-9. doi: 10.1016/j.jneuroim.2012.01.003, PMID: 22325826.

38) Tuzun E, Saini SS, Morgan BP, Christadoss P. Complement regulator CD59 deficiency fails to augment susceptibility to actively induced experimental autoimmune myasthenia gravis. J Neuroimmunol. 2006; 181(1-2): 29-33. doi: 10.1016/j.jneuroim.2006.07.016, PMID: 17056125.

39) Bouneaud C, Kourilsky P, Bousso P. Impact of negative selection on the T cell repertoire reactive to a selfpeptide: a large fraction of $\mathrm{T}$ cell clones escapes clonal deletion. Immunity. 2000; 13(6): 829-40. doi: 10.1016/S1074-7613(00)00080-7.

40) Workman CJ, Szymczak-Workman AL, Collison LW, Pillai MR, Vignali DA. The development and function of regulatory T cells. Cell Mol Life Sci. 2009; 66(16): 2603-22. doi: 10.1007/s00018-009-0026-2, PMID: 19390784, PMCID: PMC2715449.

41) Baecher-Allan C, Hafler DA. Human regulatory $T$ cells and their role in autoimmune disease. Immunol Rev. 2006; 212: 203-16. doi: 10.1111/j.0105-2896.2006.00417.x, PMID: 16903916.

42) Torgerson TR. Regulatory T cells in human autoimmune diseases. Springer Semin Immunopathol. 2006; 28(1): 63-76. doi: 10.1007/s00281-006-0041-4, PMID: 16902772.

43) Buckner JH. Mechanisms of impaired regulation by CD4(+)CD25(+)FOXP3(+) regulatory $\mathrm{T}$ cells in human autoimmune diseases. Nat Rev Immunol. 2010; 10(12): 849-59. doi: 10.1038/nri2889, PMID: 21107346, PMCID: PMC3046807.

44) Moes N, Rieux-Laucat F, Begue B, Verdier J, Neven B, Patey N, et al. Reduced expression of FOXP3 and regulatory T-cell function in severe forms of early-onset autoimmune enteropathy. Gastroenterology. 2010; 139(3): 770-8. doi: 10.1053/j.gastro.2010.06.006, PMID: 20537998.

45) Valencia X, Yarboro C, Illei G, Lipsky PE. Deficient CD4+CD25high T regulatory cell function in patients with active systemic lupus erythematosus. J Immunol. 2007; 178(4): 2579-88. doi: 10.4049/jimmunol.178.4.2579, PMID: 17277168 .

46) Venken K, Hellings N, Thewissen M, Somers V, Hensen K, Rummens JL, et al. Compromised CD4+ $\mathrm{CD} 25$ (high) regulatory $\mathrm{T}$-cell function in patients with relapsing-remitting multiple sclerosis is correlated with a reduced frequency of FOXP3-positive cells and reduced FOXP3 expression at the single-cell level. Immunology. 2008; 123(1): 79-89. doi: 10.1111/j.1365-2567.2007.02690.x, PMID: 17897326, PMCID: PMC2433271.

47) Sakaguchi S, Miyara M, Costantino CM, Hafler DA. FOXP3+ regulatory T cells in the human immune system. Nat Rev Immunol. 2010; 10(7): 490-500. doi: 10.1038/nri2785, PMID: 20559327.

48) Kemper C, Atkinson JP. T-cell regulation: with complements from innate immunity. Nat Rev Immunol. 2007; 7(1): 9-18. doi: 10.1038/nri1994, PMID: 17170757.

49) Walport MJ. Complement. Second of two parts. N Engl J Med. 2001; 344(15): 1140-4. PMID: 11297706.

50) Walport MJ. Complement. First of two parts. N Engl J Med. 2001; 344(14): 1058-66. PMID: 11287977.

51) Farkas I, Baranyi L, Ishikawa Y, Okada N, Bohata C, Budai D, et al. CD59 blocks not only the insertion of C9 into MAC but inhibits ion channel formation by homologous C5b-8 as well as C5b-9. J Physiol. 2002; 539(Pt 2): 537-45. doi: 10.1113/jphysiol.2001.013381, PMID: 11882685, PMCID: PMC2290142.

52) Lublin DM, Atkinson JP. Decay-accelerating factor: biochemistry, molecular biology, and function. Annu Rev Immunol. 1989; 7: 35-58. doi: 10.1146/annurev.iy.07.040189.000343, PMID: 2469439.

53) Porter JD, Khanna S, Kaminski HJ, Rao JS, Merriam AP, Richmonds CR, et al. Extraocular muscle is defined by a fundamentally distinct gene expression profile. Proc Natl Acad Sci U S A. 2001; 98(21): 12062-7. doi: 10.1073/pnas.211257298, PMID: 11572940, PMCID: PMC59827. 